\title{
The dayside high-latitude trough under quiet geomagnetic conditions: Radio tomography and the CTIP model
}

\author{
S. E. Pryse ${ }^{1}$, K. L. Dewis ${ }^{1}$, R. L. Balthazor ${ }^{2}$, H. R. Middleton $^{1}$, and M. H. Denton ${ }^{1,3}$ \\ ${ }^{1}$ Institute of Mathematical and Physical Sciences, University of Wales Aberystwyth, UK \\ ${ }^{2}$ Department of Applied Mathematics, University of Sheffield, UK \\ ${ }^{3}$ Now at: Los Alamos National Laboratory, USA
}

Received: 20 July 2004 - Revised: 1 March 2005 - Accepted: 3 March 2005 - Published: 3 June 2005

\begin{abstract}
The dayside high-latitude trough is a persistent feature of the post-noon wintertime auroral ionosphere. Radio tomography observations have been used to map its location and latitudinal structure under quiet geomagnetic conditions $\left(K_{p} \leq 2\right)$ near winter solstice. The trough is also a clear feature in the ion density distribution of the Coupled Thermosphere-Ionosphere-Plasmasphere model (CTIP) under similar geophysical conditions. Comparisons of the measured and modelled distributions show that the plasma production equatorward of the trough is mainly controlled by solar radiation, but there are also other processes maintaining the equatorward trough-wall that are open to debate. The poleward trough-wall is produced by particle precipitation, but the densities are significantly overestimated by the model. At the trough minimum the observed densities are consistent with low nighttime densities convecting sunward to displace the higher daytime densities, but this is not borne out by the CTIP model. The study shows the potential of combining radio tomography and modelling to interpret the balance of the physical processes responsible for large-scale structuring of the high-latitude ionosphere, and highlights the role of tomographic imaging in validating and developing physical models.
\end{abstract}

Keywords. Ionosphere (Ionization mechanisms; Modeling and forecasting) - Radio science (Ionospheric physics)

\section{Introduction}

The high latitude ionosphere is a structured medium containing irregularities in electron density over an extended range of horizontal spatial scales. Central to the current study is the dayside high-latitude trough in the post noon sector (Whalen, 1989; Rodger et al., 1992), comprising a band of depleted densities confined in latitude but extended in longitude. The feature has not been studied extensively, a likely

Correspondence to: S. E. Pryse

(sep@aber.ac.uk) consequence of the lack of ionospheric observations at these inhospitable geographic locations. Ground-based measurements by a network of ionospheric sounders made in December 1958 during the International Geophysical Year (IGY) are reported by Whalen $(1987,1989)$. These showed the trough to be located at latitudes poleward of $70^{\circ}$ magnetic latitude during quiet conditions, but to expand to lower latitudes at times of higher activity. A longitudinal dependence in the trough location was attributed to the offset between the geographic solar terrestrial reference frame and the geomagnetic frame in which the high-latitude convection pattern resides. Whalen (1989) proposed that the trough occurred in regions of sunward convective plasma transport, with low-density nighttime plasma displacing high-density daytime plasma. In-situ satellite observations of the trough at high altitudes under quiet geomagnetic conditions were included in the study of Tulunay and Grebowsky (1978), showing a midday trough near the shell $\mathrm{L}=9$, and tomographic results from a 2-week campaign near solar minimum showed the trough to be north of $70^{\circ} \mathrm{CGM}$ when geomagnetic conditions were extremely quiet, but to migrate to lower latitudes with increasing activity (Pryse et al., 1998). Observations by incoherent scatter radar of high-latitude dayside troughs during active conditions were reported by Evans et al. (1983) and Holt et al. (1984). In these studies the trough had migrated to lower latitudes, and its formation was attributed to plasma erosion associated with intense electric fields.

Routine measurements of the ionospheric plasma distribution in the remote auroral and polar regions have been scarce, mainly confined to spot $\mathrm{NmF} 2$ measurements from ionospheric sounders and in-situ topside satellite data. Radio tomography (Kunitsyn and Tereshchenko, 2003; Pryse, 2003 and references therein) is a relatively new technique for imaging the spatial distribution of the ionospheric plasma over extended height-versus-latitude planes. It is particularly adept at imaging the plasma distribution in regions of density troughs (Andreeva et al., 1990; Kersley et al., 1997) and enhancements (Moen et al., 1998; Walker et al., 1999; Pryse et al., 2000). Routine radio tomography measurements lead to 


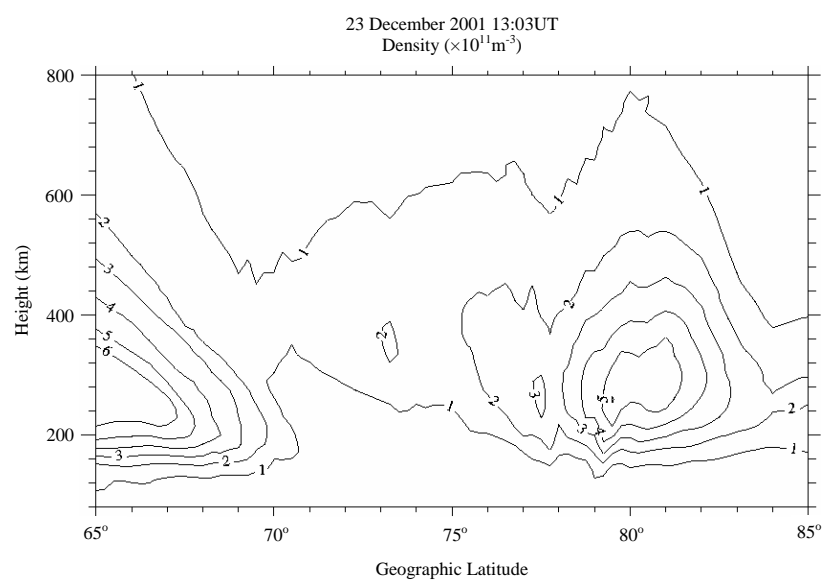

Fig. 1. Tomography image from a satellite pass crossing a latitude of $75^{\circ} \mathrm{N}$ at 13:03 UT on 23 December 2001 .

coverage of the ionosphere at all Universal Times, seasons, geomagnetic and solar conditions. The technique gives wide spatial coverage from a limited number of ground stations and is ideal for monitoring the remote inaccessible regions of the high latitudes. It is used in the current study to provide the general latitudinal spatial distribution of the dayside trough under quiet geomagnetic conditions near winter solstice and solar maximum.

The basic physics and chemistry of ionisation production and loss in the dayside auroral regions are reasonably well understood. However, the actual electron density structure present in a given situation depends on the relative contributions of various processes such as photoproduction, particle precipitation and large-scale electrodynamic drift, with the balance of the effects remaining an open question that needs to be addressed. Ionospheric models such as the Coupled Thermosphere Ionosphere Plasmasphere model (Quegan et al., 1982; Fuller-Rowell et al., 1984) and the Utah State University time dependent ionospheric model (Sojka et al., 1981) have been used to investigate the interplay of these influences on the plasma. Sojka et al. (1990) modelled low densities from the nightside being convected sunward in the dusk convection cell to produce a depleted dayside trough as suggested earlier by the IGY observations (Whalen, 1989), while Fuller-Rowell et al. (1991) studied the effects of particle precipitation and magnetospheric convection on the high latitude ionosphere by systematically "switching-off" their contributions in the model. To date, only a limited number of studies have been made of comparisons between model output and experimental observations at auroral and polar latitudes. For example, Moffett and Quegan (1983) in their review compared the consensus of experimental results for the mid-latitude trough, believed to be the nightside extension of the dayside trough, while Schoendorf et al. (1996) compared electron densities measured in the auroral region by the EISCAT incoherent scatter radar under moderately disturbed geomagnetic conditions with model output. These studies produced encouraging results on the potential of models to reproduce the observed densities, but also highlighted that uncertainties in the input parameters at high latitudes are a limitation to modelling, in particular to obtain agreement at all UTs and geographic locations.

The aim of this current study is to combine model and experimental observations to elucidate the interplay between the physical processes responsible for the formation of the post-noon high latitude trough, in particular the roles of photoproduction, particle precipitation and high-latitude convection. Attention is confined to the baseline conditions of winter solstice and quiet geomagnetic activity. An extended set of tomographic images from December 2001 provides average latitudinal distributions of plasma density over a 6-h interval of UTs. Comparisons with the output from the CTIP model are used to interpret the balance of the physical processes. Standard inputs are used for the model that are appropriate for the geophysical conditions, and no attempt is made to adapt the model or the available inputs for improved agreement with the observations. To our knowledge this is the first systematic comparison of the model densities at high latitudes with averaged observations spanning a range of latitudes and a range of UTs.

\section{Radio Tomography}

The radio tomography experiment operated by the University of Wales Aberystwyth comprises a chain of receivers at four locations in northern Scandinavia at $\mathrm{Ny}$ Ålesund $\left(78.9^{\circ} \mathrm{N}, 12.0^{\circ} \mathrm{E}\right)$, Longyearbyen $\left(78.2^{\circ} \mathrm{N}\right.$, $\left.15.7^{\circ} \mathrm{E}\right)$, Bjørnøya $\left(74.5^{\circ} \mathrm{N}, 19.0^{\circ} \mathrm{E}\right)$ and Troms $\varnothing\left(69.8^{\circ} \mathrm{N}\right.$, $\left.19.0^{\circ} \mathrm{E}\right)$. These monitor the phase coherent signals from the polar orbiting satellites in the Navy Ionospheric Monitoring System (NIMS), previously known as the Navy Navigational Satellite System (NNSS), and enable the measurement of total electron content along a large number of intersecting satellite-to-receiver ray-paths. Inversion of the data yields the distribution of electron density over a meridional section of the high-latitude ionosphere. Figure 1 shows as an example the spatial structure of the plasma, measured during a north-to-south satellite pass on 23 December 2001, with the satellite crossing latitude $75.0^{\circ} \mathrm{N}$ at 13:03 UT. The pixel dimensions for the reconstruction were $0.25 \mathrm{deg}$ latitude by $15 \mathrm{~km}$ altitude. Photoionisation gives rise to enhanced densities at the lower latitudes of the field-of-view, with densities generally decreasing with increasing latitude. Enhanced densities also occur in the auroral region at the higher latitudes, separated from the photoionisation by a trough centred near $73^{\circ} \mathrm{N}$.

Tomographic images were reconstructed for all satellite passes with maximum elevation above $40^{\circ}$ that were monitored at two or more sites between 08:30 UT and 14:30 UT in December 2001 under quiet geomagnetic conditions $\left(K_{p} \leq 2\right)$. The resulting images were binned into onehour intervals of UT. The analysis focussed on the horizontal (latitudinal) spatial structure of the ionosphere, and the density at the peak of the F2 region was used as reference 
for comparisons with the model. For each reconstruction in all UT bins, the latitudinal variation of the electron density at the altitude of the F-region peak density was determined at latitude increments of $0.25 \mathrm{deg}$. The average latitudinal density variation was then found for each UT bin. Those corresponding to the time interval 11:30-12:30 UT (labelled 12:00 UT) are shown in Fig. 2 as an example, together with the median values on which outlying traces have less of an effect. The uncertainty bars indicate the inter-quartile ranges for each 0.25 deg latitude step. Figures $3 \mathrm{a}-\mathrm{f}$ show the median curves for all six time bins labelled 09:00 UT to 14:00 UT. The number of passes corresponding to each bin is indicated on the relevant panel. All traces reveal a distinct trend of decreasing density with increasing latitude above $65^{\circ} \mathrm{N}$ that forms the equatorward wall of the high-latitude trough, although by 14:00 UT the wall is displaced significantly equatorward and is almost out of the field-of-view. The ionisation of the wall is dominated by photoionisation, with the solar control being revealed by the density values at $65^{\circ} \mathrm{N}$ maximising at about $9 \times 10^{11} \mathrm{~m}^{-3}$ near 11:00 UT and by the wall moving out of the field-of-view as the solar zenith angle increases with time. In contrast, the poleward side of the trough is a weak feature with densities reaching only $2 \times 10^{11} \mathrm{~m}^{-3}$ at 09:00 UT and 10:00 UT but increasing to some $4 \times 10^{11} \mathrm{~m}^{-3}$ at the later times. The modestly increased densities of the poleward wall are the effect of the structured ionisation at the higher latitudes. The trough minimum migrates equatorward from about $79^{\circ} \mathrm{N}$ at 09:00 UT to near $70^{\circ} \mathrm{N}$ at 14:00 UT, with minimum densities of about $1 \times 10^{11} \mathrm{~m}^{-3}$ in the plots for the earlier times, but marginally increased from 12:00 UT.

\section{Coupled thermosphere ionosphere plasmasphere model (CTIP)}

The high-latitude ionosphere is to varying degrees influenced by solar EUV radiation, the precipitation of charged particles, electrodynamic drift, diffusion, thermospheric winds and temperature-sensitive chemical reactions. The CTIP model can be used to investigate the interplay between these various elements in the interpretation of the density distribution observed by the tomography experiment. The development of the model at the University of Sheffield and University College London is well documented, covering early work on the thermospheric model (Fuller-Rowell and Rees, 1980, 1983) and its integration with the plasmasphere and the high-latitude ionospheric model with plasma convection and precipitation energy inputs (Quegan et al., 1982). The integration of the models provided a powerful tool to investigate the interplay between the thermosphere and ionosphere (Fuller-Rowell et al., 1987). In brief, coupled equations of momentum, energy and continuity are solved at fixed grid points to calculate values of density, temperature and velocity of the neutral atmosphere, and of the $\mathrm{O}^{+}$and $\mathrm{H}^{+}$ions on open flux tubes at high latitudes and closed flux tubes in the plasmasphere. The output quantities, of ion and neutral densities, temperatures, and velocities as well as derived quanti-

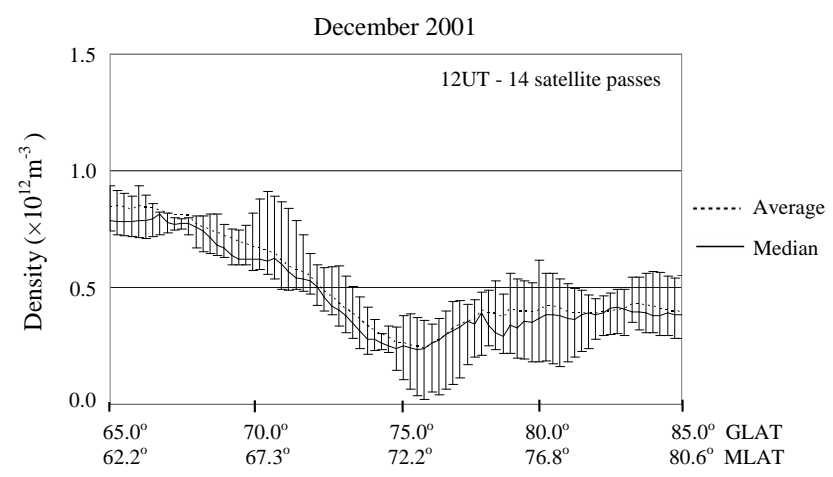

Fig. 2. Average and median electron densities at the F-region peak from the tomography images under quiet geomagnetic conditions between 11:30 UT and 12:30 UT in December 2001. The uncertainty bars indicate the inter-quartile ranges.

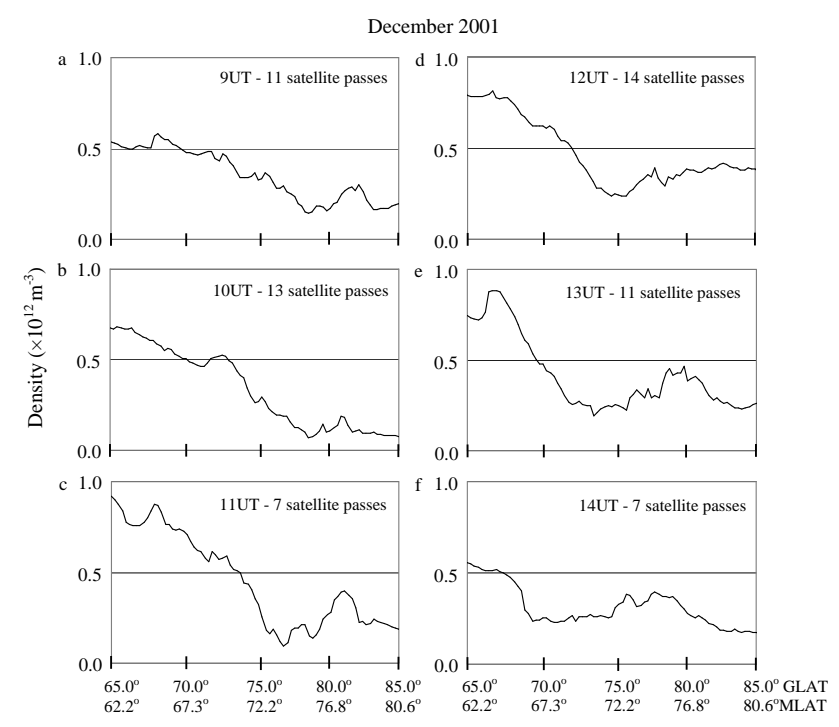

Fig. 3. Median values for the tomography electron densities at the F-region peak under quiet geomagnetic conditions within each onehour bin between 08:30 UT and 14:30 UT in December 2001.

ties such as Joule heating are determined on a geocentric grid with a resolution of $2^{\circ}$ latitude, $18^{\circ}$ longitude and one scale height from a lower boundary fixed at $80 \mathrm{~km}$ at $1 \mathrm{~Pa}$. Since the early development of the coupled model, various adaptations have been carried out at the University of Sheffield, University College London and the Space Environment Laboratory, USA. The model used in the current study is the Sheffield University CTIP model. Inputs were chosen from the standard selection available to the model appropriate to the geophysical conditions of observations.

The day number was set to 347, 13 December 2001, taken to be representative of the month of December. The f10.7 index was set to 213 , the average solar condition of the month. The precipitation energy input was according to the classification of DMSP satellite measurements by Hardy et al. (1985), with a $K_{p}$ level of 1 being selected for the lowest 


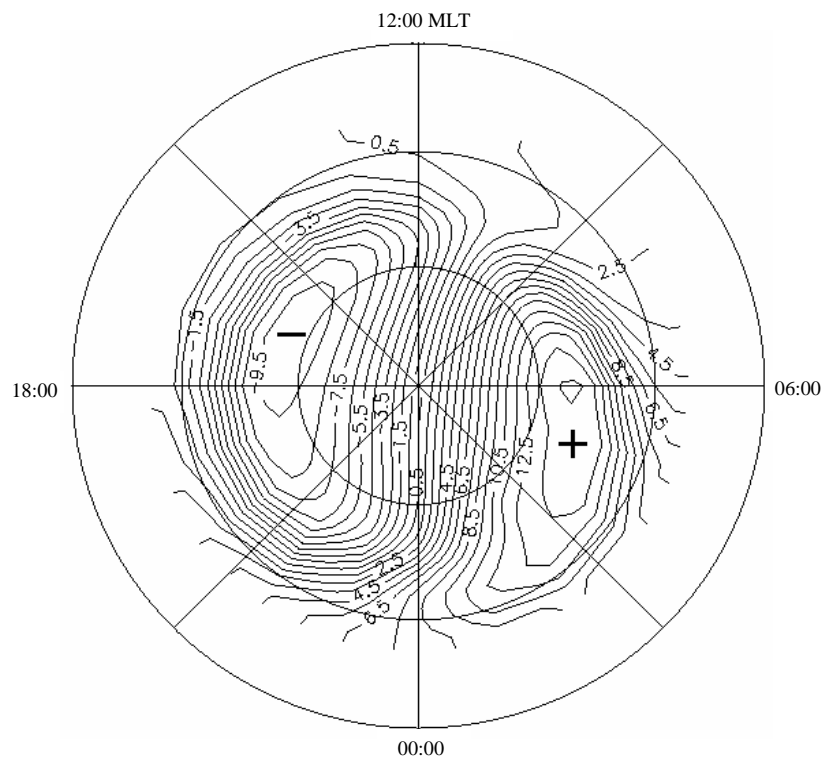

Fig. 4. Electric potential pattern used in the CTIP model to describe the high-latitude convection pattern. The latitude coverage of the plot is from $60^{\circ}$ MLAT to $90^{\circ}$ MLAT and the cross-polar potential is approximately $25 \mathrm{kV}$.

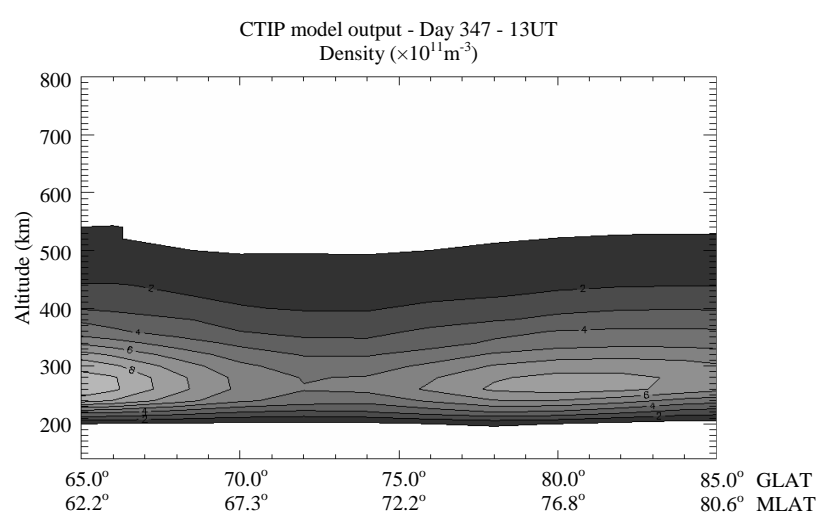

Fig. 5. Ionisation density distribution at $18^{\circ} \mathrm{E}$ and 13:00 UT from the CTIP model run with precipitation and convection input $\left(\mathrm{M}_{p c}\right)$ as a function of latitude and altitude.

level of precipitation input permitted by the model. A range of 37 electric potential patterns, based on Millstone Hill plasma flow measurements (Foster et al., 1986), were available to describe the high-latitude convection pattern poleward of $67^{\circ}$ MLAT. The selected pattern, shown in Fig. 4, has a standard 2-cell configuration, corresponding to antisunward cross-polar flow and return flows at lower latitudes. It has a cross polar-cap potential of about $25 \mathrm{kV}$, commensurate with a low geomagnetic activity. Of relevance to the current study is the post-noon section of the dusk cell with antisunward flow in the polar regions, flow reversal centred near $78^{\circ}$ MLAT $\left(81^{\circ} \mathrm{N}\right)$ and return flow at geomagnetic latitudes broadly covering $70^{\circ}$ MLAT to $75^{\circ}$ MLAT $\left(73^{\circ} \mathrm{N}\right.$ to $78^{\circ} \mathrm{N}$ ). Equatorward of the high-latitude potential pattern the

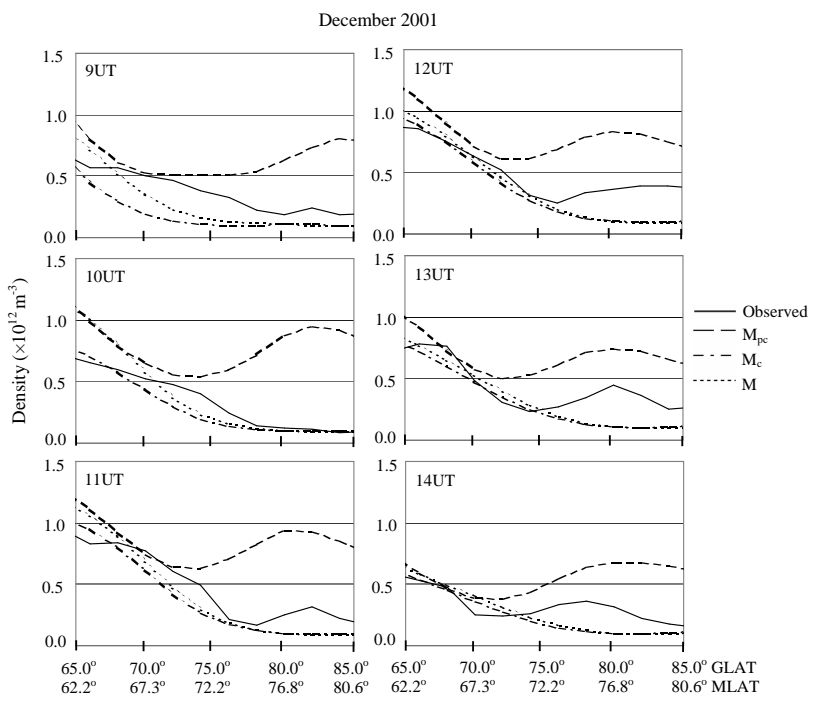

Fig. 6. Ionisation densities from the CTIP model at $18^{\circ} \mathrm{E}$ and altitude of $260 \mathrm{~km}$ at hourly intervals from 09:00 UT to 14:00 UT with precipitation and convection inputs, $\mathbf{M}_{p c}$, (long dashed curve), convection input and precipitation switched off, $\mathbf{M}_{c}$, (long-short dashed curve) and no precipitation and no convection input, $\mathrm{M}$, (short dashed curve). Also shown are the corresponding median electron densities from the tomography observations (solid curve) averaged over $2^{\circ}$ latitude for comparison with the model output.

plasma co-rotates with the Earth.

A typical latitude-versus-height cross-section through the post-noon high-latitude ionosphere along $18^{\circ} \mathrm{E}$ at 13:00 UT is shown in Fig. 5 for a run of the model $\left(\mathrm{M}_{p c}\right)$. It shows enhanced densities at the equatorward and poleward sides of a trough with minimum near $72^{\circ} \mathrm{N}\left(69^{\circ}\right.$ MLAT $)$, with the F2 density peak at an altitude of $260 \mathrm{~km}$. To a first approximation there is broad likeness between this and the tomography image at a similar UT in Fig. 1. However, there are also clear differences, with the observed ionisation levels being larger in the modelled ionosphere. Such disparities will be considered further in the following section, with comparisons made between the observations and model output. Two further model runs were performed, one in which the precipitation energy source was turned off and convection retained $\left(\mathrm{M}_{c}\right)$ and the other with both precipitation and convection switched off (M).

\section{Comparison of tomography and modelled densities}

The median values of the observed tomography peak densities for the six UT epochs of interest are reproduced in the six panels of Fig. 6. These have been averaged over 2 degrees latitude for comparison with the model output. The distributions of the F-region peak ionisation densities along the $18^{\circ} \mathrm{E}$ meridian for the model run with both precipitation and convection, $\mathbf{M}_{p c}$, are also shown in the appropriate UT panels. Included for reference are the corresponding modelled densities for the runs with convection and without precipitation, 
$\mathrm{M}_{c}$, and without both precipitation and convection, $\mathrm{M}$. Broad agreement occurs between the observations and the modelled values at the lowest latitudes at all UTs but the values deviate substantially at the higher latitudes.

The observed densities on the left-hand-side of the panels between 09:00 UT and 11:00 UT, and to a lesser extent those at 12:00 UT, show a decrease with increasing latitude that is more gradual than in the $\mathrm{M}$ curve. Thus observed densities are significantly higher on the equatorward trough-wall than predicted by solar illumination alone. This is then followed by a decrease at a steeper gradient in the observed densities into the trough minimum, where levels as low as the modelled curve are attained. This will be discussed at a later stage. The full model $\mathbf{M}_{p c}$ yields density levels generally higher than those observed. It appears that the precipitation energy not only increases the density within the source region, but also has an indirect influence of increasing densities at lower latitude.

In the northern field-of-view, within the precipitation source region, the model produces densities that are substantially larger than the observations. The poleward side of the trough is identified in the observed densities as enhancements above the background density levels of $\mathrm{M}$, which become more apparent with increasing UT. At 09:00 UT and 10:00 UT the higher level is clearer in the densities prior to averaging over latitude (Fig. 3). Modelled densities $\mathbf{M}_{p c}$ on the poleward side maximise near $81^{\circ} \mathrm{N}\left(78^{\circ} \mathrm{MLAT}\right)$ near the convection reversal of the afternoon cell, but these are clearly too large. Two possible factors that would lead to a reduction in the modelled densities in this region are lower precipitation energy input to reduce direct ionisation production, and increased high-latitude convection flow for greater ionisation loss. In the case of the precipitation, the lowest level had been selected in the model run and it was not possible to reduce the effect further other than by switching the precipitation off. The effect of the high-latitude flow was investigated by changing the convection pattern to a two-cell pattern with a larger cross-polar potential. Inspection of the cross-polar potentials on the Convection Map Archive of the SuperDarn website (http://superdarn.jhuapl.edu) for the times of interest, revealed values that were generally lower than $70 \mathrm{kV}$, and below $50 \mathrm{kV}$ for some $70 \%$ of the times under consideration. Hence a convection pattern with an extreme crosspolar potential of some $70 \mathrm{kV}$ was selected. The resulting modelled peak F-region densities for 11:00 UT are shown in Fig. 7, together with the corresponding modelled densities, $\mathbf{M}_{p c}$, and the averaged observations. The introduction of this drastic measure for the cross-polar potential produced densities reduced at northern latitudes to levels comparable to the observations, but it also reduced the densities over the entire latitude range to an extent that the trough is not readily identified. It is therefore unlikely that the observed levels in the northern field-of-view are explained entirely by a stronger convection flow.

The densities in the trough minimum were overestimated by model $\mathrm{M}_{p c}$ with the observed values being some two to three-fold smaller and essentially at or below the level of

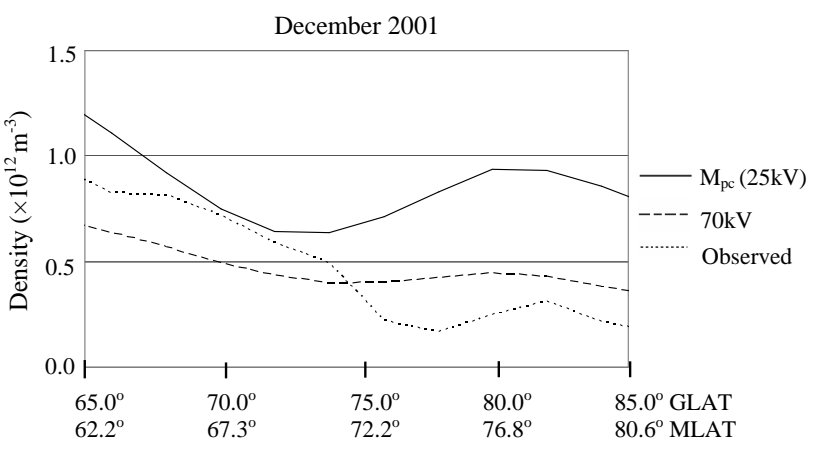

Fig. 7. Ionisation densities from the CTIP model at $18^{\circ} \mathrm{E}$ and altitude of $260 \mathrm{~km}$ at 11:00 UT from the model run $\mathrm{M}_{p c}$ with crosspolar potential of about $25 \mathrm{kV}$ (solid curve) and identical model run but with an electric potential pattern with a cross-polar potential of about $70 \mathrm{kV}$ (long dashed curve). Also shown are the corresponding median electron densities from the tomography observations averaged over $2^{\circ}$ latitude (short dashed curve).

the photoionisation. An equatorward movement of the observed trough minimum occurs with a displacement from about $80^{\circ} \mathrm{N}$ at 09:00 UT to some $70^{\circ} \mathrm{N}$ at 14:00 UT. A similar equatorward migration is also apparent in modelled densities $\mathbf{M}_{p c}$, although the corresponding latitudinal range is reduced from approximately $74^{\circ} \mathrm{N}$ to $71^{\circ} \mathrm{N}$.

\section{Discussion}

The general consensus portrayed in the literature is that the dayside trough is formed by photoionisation on the equatorward wall, precipitation on the poleward wall, and cold lowdensity plasma at the minimum that is carried by the sunward return flow from the nightside into the dayside sector. This study supports this in part, but also reveals that the balance and interplay between the different factors is not fully understood.

The observed densities at the equatorward extreme of the region of interest near $65^{\circ} \mathrm{N}$ are supported by the model output. This region is likely to behave akin to the mid-latitude ionosphere, where solar control is the influencing factor. On the equatorward trough wall the densities are expected to decrease in response to an increasing solar zenith angle, however, the observed densities are maintained at a higher level than anticipated. This may be explained in terms of the interaction of photoproduction and the high-latitude convection pattern. Near magnetic noon (09:00 UT) the higher densities can be explained to be those of the tongue-of-ionisation that draws photoionisation from lower latitudes towards the polar region (Sims et al., 2005). At later times they may be attributed to plasma exposed to sunlight for an extended time as it moves very slowly sunward at the equatorward extreme of the return flow of the afternoon cell (Pryse et al., 2004). However, neither of these explanations is borne out in the model runs, with the density levels of the run with solar production and convection, $\mathrm{M}_{c}$, being lower than those of the 


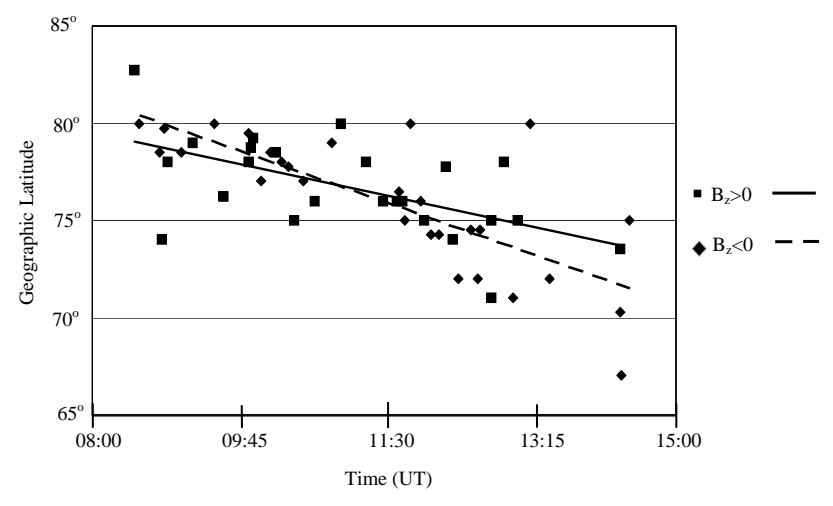

Fig. 8. Scatter plot of the latitude of the trough minimum obtained from tomography images between 08:30 UT and 14:30 UT, categorised according to IMF $B_{z}$ positive (squares and solid line) and $B_{z}$ negative (diamonds and dashed line).

run with only the solar production, M. A further explanation is that it may be an indirect effect of precipitation, with energy input at the higher latitudes affecting the thermospheric morphology with the neutral wind flow driving ionisation up the magnetic field to regions of less molecular species and hence slower recombination rate (Fuller-Rowell et al., 1991). Increased levels are given by the full model run $\mathrm{M}_{p c}$ that includes the effect of precipitation in addition to convection, but this fails to model the observed steeper reduction of density into the trough minimum.

From 09:00 UT to 12:00 UT the densities at the trough minimum revert to the densities modelled in the absence of precipitation, with those at 13:00 UT and 14:00 UT being even smaller. The low densities in the trough have been modelled by Sojka et al. (1990) and attributed by Whalen (1987, 1989) to low densities from the nightside being carried in the return sunward flow of the dusk cell to displace the higher densities of the dayside. This interpretation is supported in the current study by the trough residing in the return flow of the cell, and by the density measurements at 13:00 UT and 14:00 UT being lower than those modelled with only solar production as input, $\mathrm{M}$. However, the model run $\mathrm{M}_{c}$, which accommodates convection in addition to the solar production, fails to model densities significantly lower than those of $\mathrm{M}$ at the relevant times.

The main difference between the observations and modelled density levels $\mathbf{M}_{p c}$ occurs on the poleward side of the trough. While both reveal the effect of the precipitation, the model significantly overestimates the densities. It is unlikely that the large densities are explained by the cross-polar potential being too small, although this could be a contributory effect. The disparity is mainly because of energy input from precipitation being too high. In this current study, the precipitation was set to the lowest level accommodated by the model, and hence could not be reduced further other than by switching off. This level accommodates the Hardy et al. (1985) statistical precipitation category for $K_{p}=1-, 1$ and $1+$, which tend to be at the higher extreme of the condi- tion of $K_{p} \leq 2$ used for the classification of the observational data. The inclusion of data for condition $K_{p}=0$, but omission of the condition from the modelling, may partly account for the observed densities being smaller than those modelled, however it is unlikely to be the sole reason. It can also be noted, although outside the main scope of the present study, that subsidiary investigations into the effects of the precipitation levels on the modelled density reveal that variations in the precipitation flux and average energy, consistent with the low $K_{p}$ values, can lead to an uncertainty in the auroral electron density of up to an order of magnitude. In the longer term, the effect of precipitation input in the model needs to be addressed, although in the first instance the existence of other disparities need to be established at different geomagnetic activity levels, universal times and geographic locations, so that any changes to the model are considered within the global framework rather than tuning the model to this data set alone (Schoendorf et al., 1996). Radio tomography offers the potential for such comparisons, with long term observations being made in the European sector and also by the recently established International Ionospheric Tomography Community with receivers in the high-latitude sector in Alaska, Greenland, and Europe (Kersley et al., 2005).

This investigation has aimed to look at the observations in a semi-statistical fashion, rather than on the basis of observations from individual passes. Measurements from a total of 63 passes were used. Attempts to increase the number of passes by including data from other winter months were abandoned for this particular study, when it became clear that observations from November 2001 were yielding significantly increased density levels because of increased solar production. Similarly, observations from the month of December in other years were not included because of the effect of solar activity on the density levels. The geophysical conditions for the observations were hence restricted so that they were as representative as possible of the input conditions used for the model runs. Such comparisons pave the way for systematically addressing the model inputs, in particular uncertainties in the electric potentials and in the intensity and position of the auroral energy source (Moffett and Quegan, 1983).

The study has classified the data for quiet conditions in terms of the global $K_{p}$ index, this being the parameter that sets the level of precipitation input in the model. However, the high-latitude ionosphere is mainly driven by the interaction of the interplanetary magnetic field (IMF) with the Earth's magnetic field, with the auroral emissions and density structures showing a dependence on the orientation and strength of the $B_{z}$ component of the IMF. An investigation of the effect of the polarity of $B_{z}$ revealed insignificant differences in the trough morphology under $B_{z}$ positive and negative. Figure 8 is a scatter plot of the latitude of the trough minimum versus UT, where each point relates to an individual tomographic image with a discernable trough minimum and is categorised in terms of $B_{z}$ positive or negative. No clear distinction is revealed in the location of the trough under $B_{z}>0$ and $B_{z}<0$, but this is not surprising as the trough 
location and structure at the time of interest is located in the dusk viscous cell, with precipitation straddling the flow reversal and the return sunward flow at lower latitudes. Such a cell is characteristic of both $B_{z}$ positive and negative under quiet conditions (Cowley, 1998).

\section{Conclusions}

In conclusion, average density distributions from tomographic observations have been obtained that show the latitudinal characteristics of the dayside high-latitude trough in the post-magnetic-noon sector under quiet geomagnetic conditions near solar maximum. The latitudinal variations have been compared with those given by the CTIP model under similar conditions, revealing that:

- Densities well equatorward of the trough were controlled by solar input,

- Densities on the equatorward trough-wall were larger than expected by solar input alone, and consequently resulted in a steep gradient leading into the trough minimum. The model did not reproduce this effect.

- Densities at the trough minimum between 09:00 and 12:00 UT were comparable to those of solar production. At later times the observed densities were lower than those of solar production, supporting the explanation proposed by Whalen (1989) of low densities being carried sunward from the nightside into the dayside.

- Densities forming the poleward trough wall were produced by precipitation, but the CTIP model significantly over estimated the ionisation levels. The precipitation energy input in the model increased the density levels over the entire latitude range of interest.

The latitudinal variation of the density through the postnoon dayside trough is clearly a balance of solar production, high-latitude convection, and intensity and location of precipitation energy input. However, this study shows that the details of the balance of the processes are not full understood, with the model not replicating the observed densities. The combination of radio tomography observations and modelling output has the potential to interpret the roles of these physical processes responsible for the large-scale ionisation structure in the ionosphere, and to validate and develop the physical models of the high-latitude ionosphere.

Acknowledgements. Financial support for the project was provided by the UK Particle Physics and Astronomy Research Council under grants PPA/G/O/2003/00017 and PPA/G/O/2001/00464. The assistance of the University of Troms $\varnothing$ and the Norwegian Polar Research Institute in the tomographic measurements is gratefully acknowledged. Magnetic indices were obtained from the World Data Centre, Rutherford Appleton Laboratory and the IMF data obtained from the CDAWeb. KLD acknowledges receipt of a PPARC postgraduate studentship.

Topical Editor T. Pulkkinen thanks V. Kunitzin and another referee for their help in evaluating this paper.

\section{References}

Andreeva, E. S., Galinov, A. V., Kunitsyn, V. E., Melnichenko, Y. A., Tereshchenko, E. D., Filimonov, M. A., and Chernyakov, S. M.: Radiotomographic reconstruction of ionization dip in the plasma near the Earth, J.E.T.P. Lett., 52, 145-148, 1990.

Cowley, S. W. H.: Excitation of flow in the Earth's magnetosphereionosphere system: observations by incoherent scatter radar, in Polar Cap Boundary Phenomena, (Eds.) Moen, J., Egeland, A. and Lockwood, L., NATO Advanced Study Institute Series, Kluwer Academic Press, Dordrecht, The Netherlands, 509, 127$140,1998$.

Evans, J. V., Holt, J. M., Oliver, W. L., and Wand, R. H.: On the formation of daytime troughs in the F-region within the plasmasphere, Geophys. Res. Lett., 10, 405-408, 1983.

Foster, J. C., Holt, J. M., and Musgrove, R. G.: Ionospheric convection associated with discrete levels of particle precipitation, Geophys. Res. Lett., 13, 656-659, 1986.

Fuller-Rowell, T. J., Rees, D., Quegan, S., and Moffett, R. J.: Numerical simulations of the sub-auroral F-region trough, J. Atmos. Terr. Phys., 53, 529-540, 1991.

Fuller-Rowell, T. J., Rees, D., Quegan, S., Moffett, R. J., and Bailey, G. J.: Interactions between neutral thermospheric composition and the polar ionosphere using a coupled ionospherethermosphere model, J. Geophys. Res.-Space Phys., 92, 77447748, 1987.

Fuller-Rowell, T. J., Rees, D., Quegan, S., Bailey, G. J., and Moffett, R. J.: The effect of realistic conductivities on the high latitude thermospheric circulation, Planet. Space Sci., 32, 469-480, 1984.

Fuller-Rowell, T. J. and Rees, D.: Derivation of a conservation equation for mean molecular weight for a two-constituent gas within a three-dimensional, time-dependent, model of the thermosphere, Planet. Space Sci., 31, 1209-1222, 1983.

Fuller-Rowell, T. J. and Rees, D.: A three-dimensional, timedependent, global model of the thermosphere, J. Atmos. Sci., 37, 2545-2567, 1980.

Hardy, D. A., Gussenhoven, M. S., and Holeman, E.: A statistical model of auroral electron precipitation, J. Geophys. Res.-Space Phys., 90, 4229-4248, 1985.

Holt, J. M., Wand, R. H., and Evans, J. V.: Millstone Hill measurements on 26 February 1979 during the solar eclipse and formation of a midday F-region trough, J. Atmos. Terr. Phys., 46, 251-264, 1984.

Kersley, L., Pryse, S. E., Denton, M. H., Bust, G., Fremouw, E., Conde, M., Jakowski, N., and Bailey, G. J.: Radio tomographic imaging of the northern high-latitude ionosphere on a wide geographic scale, Radio Sci., 2005 (in press).

Kersley, L., Pryse, S. E., Walker, I. K., Heaton, J. A. T., Mitchell, C. N., Williams, M. J., and Willson, C. A.: Imaging of electron density troughs by tomographic techniques, Radio Sci., 32, 1607-1621, 1997.

Kunitsyn, V. E. and Tereshchenko, E. D.: Ionospheric tomography, Springer, pp 259, 2003.

Moen, J., Berry, S. T., Kersley, L., and Lybekk, B.: Probing discrete auroral arcs by ionospheric tomography, Ann. Geophys. 16, 574-582, 1998,

\section{SRef-ID: 1432-0576/ag/1998-16-574.}

Moffett, R. J. and Quegan, S.: The mid-latitude trough in the electron concentration of the ionospheric F-layer: a review of observations and modelling, J. Atmos. Terr. Phys., 45, 315-343, 1983.

Pryse, S. E., Sims, R. W., Moen, J., Kersley, L., Lorentzen, D., 
and Denig, W. F.: Evidence for solar-production as a source of polar-cap plasma, Ann. Geophys., 22, 1093-1102, 2004,

SRef-ID: 1432-0576/ag/2004-22-1093.

Pryse, S. E.: Radio tomography: A new experimental technique, Surveys in Geophysics, 24, 1-38, 2003.

Pryse, S. E., Smith, A. M., Walker, I. K., and Kersley, L.: Multiinstrument study of footprints of magnetopause reconnection in the summer ionosphere, Ann. Geophys., 18, 1118-1127, 2000, SRef-ID: 1432-0576/ag/2000-18-1118.

Pryse, S. E., Kersley, L., Williams, M. J., and Walker, I. K.: The spatial structure of the dayside ionospheric trough, Ann. Geophys., 16, 1169-1179, 1998,

SRef-ID: 1432-0576/ag/1998-16-1169.

Quegan, S., Bailey, G. J., Moffett, R. J., Heelis, R. A., FullerRowell, T. J., Rees, D., and Sprio, R. W.: A theoretical study of the distribution of ionisation in the high-latitude ionosphere and the plasmasphere: first results on the mid-latitude trough and the light-ion trough, J. Atmos. Terr. Phys., 44, 619-640, 1982.

Rodger, A. S., Moffett, R. J., and Quegan, S.: The role of ion drift in the formation of ionisation troughs in the mid- and high-latitude ionosphere - A review, J. Atmos. Terr. Phys., 54, 1-30, 1992.

Schoendorf, J., Aylward, A. D., and Moffett, R. J.: Modelling high-latitude electron densities with a coupled thermosphereionosphere model, Ann. Geophys., 14, 1391-1402, 1996,

SRef-ID: 1432-0576/ag/1996-14-1391.
Sims, R. W., Pryse, S. E., and Denig, W. F.: Spatial structure of summertime ionospheric plasma near magnetic noon, Ann. Geophys., 23, 25-37, 2005,

SRef-ID: 1432-0576/ag/2005-23-25.

Sojka, J. J., Raitt, W. J., and Schunk, R. W.: A theoretical study of the high-latitude winter $\mathrm{F}$ region at solar minimum for low magnetic activity, J. Geophys. Res., 86, 609-621, 1981.

Sojka, J. J., Schunk, R. W., and Whalen, J. A.: The longitude dependence of the dayside F-region trough: A detailed model-observation comparison, J. Geophys. Res.-Space Phys., 95, 15,275-15,280, 1990.

Tulunay, Y. K. and Grebowsky, J. M.: The noon and midnight midlatitude trough as seen by Ariel 4, J. Atmos. Terr. Phys., 40, 845855, 1978.

Walker, I. K., Moen, J., Kersley, L., and Lorentzen, D.: On the possible role of cusp/cleft precipitation in the formation of polarcap patches, Ann. Geophys., 17, 1298-1305, 1999,

SRef-ID: 1432-0576/ag/1999-17-1298.

Whalen, J. A.: The daytime F layer trough and its relation to ionospheric-magnetospheric convection, J. Geophys. Res.-Space Phys., 94, 17 169-17 184, 1989.

Whalen, J. A.: Daytime F layer trough observed on a macroscopic scale, J. Geophys. Res.-Space Phys., 92, 2571-2576, 1987. 